\title{
TRAS LA TEMPESTAD, NO LLEGÓ LA CALMA: EL MEDIO VINALOPÓ ANTE LOS TEMPORALES DE SEPTIEMBRE DE 1793 $^{1}$
}

\author{
ADRIÁN GARCÍA TORRES \\ Universidad de Alicante/ Universitat d'Alacant
}

Fecha de recepción: septiembre de 2010

Fecha de aceptación: diciembre de 2010

\section{ASPE EN LA SEGUNDA MITAD DE SIGLO}

Climáticamente el siglo XVIII significó el final de la fase más álgida de la Pequeña Edad Hielo, que supuso un cambio climático sin equiparación desde la edad glacial. ${ }^{2}$ Se suele datar su inicio en 1550, mas para su fin nos encontramos con unos límites difusos que oscilan entre el tercer cuarto del setecientos o incluso hasta bien avanzada la contemporaneidad. ${ }^{3}$ Con la llegada de la nueva centuria se dio un avance hacia una fase más cálida, pero ello no significó que no se desarrollaran duros inviernos en años puntuales, como ocurrió en 1708-1709 y 1716. Esta situación se mantuvo hasta la década de los sesenta en la que se inauguró un nuevo período frío caracterizado por fuertes oscilaciones meteorológicas. Es lo que ha sido denominado como la anomalía u

1. El presente trabajo es, a grandes rasgos, un resumen de mi tesis fin de máster del Máster Historia e identidades hispánicas en el Mediterráneo Occidental (siglos XV-XIX), dirigida por el dr. Alberola Romá, a quien le agradezco su ayuda y consejos. Este trabajo forma parte de los resultados del proyecto de investigación «Riesgo y desastre natural en la España del siglo XVIII. Episodios meteorológicos extremos y sus efectos a través de la documentación oficial, la religiosidad popular y la reflexión científica» (HAR2009-11928), que cuenta con financiación del Ministerio de Ciencia e Innovación del Gobierno de España y Fondos FEDER.

2. Font Tullot, I.: Historia del clima en España. Cambios climáticos y sus causas. Madrid: Instituto Nacional de Meteorología, 1988, p. 71.

3. Para el caso alicantino ver ZAMORA PASTOR, R.: El final de la «Pequeña Edad del Hielo» en tierras alicantinas. Alicante: Universidad de Alicante, 2002. 
oscilación Maldá, ${ }^{4}$ definida por un incremento de los episodios extremados de sequías e inundaciones por precipitaciones de alta intensidad horaria, con una etapa culminante entre 1780-1795.

El inicio de la década de los cincuenta significó para la villa de Aspe el comienzo de las sucesivas catástrofes encadenadas, que derivaron en una situación de impotencia económica y una difícil subsistencia. Estos infortunios tuvieron como colofón la avenida de primeros de septiembre de 1793. Para comprender el duro golpe que significó este episodio catastrófico es necesario realizar un breve recorrido sobre otros sucesos previos y, de este modo, obtener un conocimiento del estado en el que se encontraba la villa para hacerle frente.

La década de transición hasta la nueva fase fría y de anomalía climática se inauguró con la avenida del 31 de octubre de 1751, la cual también afectó a la vecina Elche, ${ }^{6}$ y cuya repercusión tuvo una gravedad casi equiparable a la de 1793. Las aguas del río Tarafa, desbordadas, destruyeron el pequeño puente de mampostería y sillería ubicado en el paraje de Baño. ${ }^{7}$ La otra infraestructura viaria que disponían los habitantes para cruzar el barranco, la rafa-puente del Fauquí, también quedó seriamente dañada. Finalmente, las excesivas precipitaciones caídas dejaron en una precaria situación las tierras de labor y complicaron el aporte de aguas a la huerta del Aljau, al destruirse el acueducto del Hondo de las Fuentes, que atravesaba el barranco. ${ }^{8}$ Debido a esta circunstancia, desde el gobierno municipal se iniciaron las gestiones para solicitar la

4. BARRIENDOS, M.; LlASAT, C.: «El caso de la anomalía «Maldá» en la cuenca mediterránea occidental (1760-1800)», en Alberola RomÁ, A.; Olcina CANTOS, J. (eds): Desastre natural, vida cotidiana y religiosidad popular en la España moderna y contemporánea. Alicante: Publicaciones UA, 2009, pp. 253-283.

5. En lo referente a las lluvias de alta intensidad horaria y avenidas en el País Valenciano durante el siglo XVIII ver Alberola Romá, A.: Quan la pluja no sap ploure. Sequeres i riuades al País Valencià en l'edat moderna. Valencia: Publicacions Universitat de València, 2010.

6. Ramos Folques, A.: Historia de Elche. Elche: Talleres Tipográficos Lepanto, 1971, vol. II, pp. 537-539.

7. Archivo Histórico de la Diputación Provincial de Alicante (AHDPA). Correspondencia relativa a la hacienda municipal. Informes y recursos (1762-1830), legajo 12610, Certificación de Marcos Evangelio sobre el nuevo puente a realizar en el paraje del Baño. 27 de julio de 1764.

8. La villa de Aspe contaba durante el setecientos con las siguientes infraestructuras hidráulicas y viarias: La acequia del Fauquí recorría el margen derecho del río y tomaba las aguas que retenía de la rafa del Fauquí para regar las huertas de ese paraje. La acequia del Aljau se alimentaba directamente de una fuente aguas arriba de la rafa anterior y también recogía los excedentes de la acequia del Fauquí por el acueducto del Hondo de las Fuentes. Sus aguas se utilizaban en la huerta del Aljau, ubicada a la izquierda del río. Por último, la acequia de la Huerta Mayor se nutría de las aguas del río y las conducía al paraje con el mismo nombre. Por lo que hace a los viaductos, el más importante era el puente del Baño, fundamental para marchar por el Camino Real hacia la capital y a Monforte del Cid. El otro medio de salvar el barranco del Tarafa era a través de la rafa del Fauquí, que también desarrolló un papel de puente, clave para la visita a los vecinos Hondones o continuar a través del Camino Real que de Yecla enlazaba con la vía murciana hacia la capital. La mejor aproximación a los caminos y puentes de Aspe en la modernidad es la de MARTíneZ ESPAÑol, G.: Las comunicaciones, el transporte y la hospedería en el Aspe del s.XVIII. IV Premio de Investigación José Cremades 2006. Aspe: Ayuntamiento de Aspe, 2007. Para un conocimiento más detallado de las infraestructuras hidráulicas del Medio Vinalopó ver PÉREZ MEDINA, T.(coord.): El 
condonación de las contribuciones a la Corona durante un período de doce años y para el inicio de la construcción de un nuevo puente.

La situación de la villa no mejoró en los años siguientes, al ser uno de los lugares en los que la plaga de langosta hizo importantes estragos. Ésta, acaecida en los años 1756 y 1757, afectó a todo el territorio valenciano, y la sequía del año 1758 no hizo más que agravar la situación. Aspe pidió de nuevo la exención fiscal a la Corona tras alegar la pérdida durante tres años de las cosechas más importantes de la localidad. ${ }^{9}$

El daño causado por este insecto ortóptero aumentó sobremanera al coincidir con las fiebres del verano de 1757, a causa del consumo de agua en mal estado de las fuentes que emanaban en el Tarafa. La infección de las aguas se originó por su ubicación cercana a un camino cruzado por animales y por las que permanecían estancadas de las avenidas pasadas. ${ }^{10} \mathrm{La}$ aparición del tifus conllevó un alto número de enfermos y algunas muertes en una población debilitada y empobrecida.

La entrada en la década de los sesenta y el inicio de la oscilación climática coincidió con años de sequía, que en 1764 llevaron a realizar una rogativa pro pluvia. La sequedad reinante se combinó con avenidas como las de 1766 y la de 2 de octubre 1767. Ambas riadas destruyeron el puente provisional de madera, debido a su pésimo estado, y dañaron la rafa-puente del Fauquí.

Los problemas económicos que acarreaba la villa dilataron la construcción de un nuevo viaducto de mampostería en el paraje del Río. La documentación nos informa de un proyecto elaborado por Marcos Evangelio en el año 1764, aunque desechado por su alto coste. El plan que finalmente se implementó fue una propuesta de la villa más acorde con su situación económica, que fue aprobado y rematado en 1767. En los años ulteriores, la reconstrucción avanzó con problemas a causa de la falta de fondos de la villa; sin embargo, quedó congelada al superarse el precio fijado. ${ }^{11}$ El paro de la obra se alargaría desde 1769 a más allá de la mitad de los setenta.

La nueva década comenzó con una helada que afectó al proceso de maduración de la uva, por lo que el síndico personero de la villa propuso que se retrasara su vendimia hasta pasada la festividad de San Francisco (4 de octubre), momento en el que los vinos alcanzarían una graduación óptima para poder elaborar aguardientes. ${ }^{12}$ El resto de la década se caracterizó por sequías continuadas.

patrimoni històric comarcal (actes)/ II congrés d'Estudis del Vinalopó. Petrer: Centre d'Estudis Locals del Vinalopó, 2005.

9. Alberola RomÁ, A.: «Procesiones, rogativas, conjuros y exorcismos: el campo valenciano ante la plaga de langosta de 1756»), en Revista de Historia Moderna: Anales de la Universidad de Alicante, $\mathrm{n}^{\circ} 21$ (2003), p. 392.

10. MARTíneZ EsPAÑOL, G.: «La epidemia de 1757», en La Serranica, n. ${ }^{\circ} 43$ (2008), pp. $70-71$.

11. AHDPA: Correspondencia relativa a la hacienda municipal. Informes y recursos (1762-1830), legajo 12610, Respuesta de Manuel Bezerra al intendente Sebastián Gómez de Torre. Madrid, 10 de mayo de 1774 .

12. Cremades Cremades, M.: Aspe, Novelda y Monforte. 1966, p. 84. 
La llegada de los ochenta fue el punto de partida de la fase más grave de la anomalía climática y dejó a la villa de Aspe en una situación más penosa de la que ya arrastraba. A las lluvias de 1783, les siguieron las copiosas precipitaciones del 15 de octubre de 1785, que se convirtieron en una avenida que arrasó las cañerías que transportaban agua potable a la ciudad, las acequias de riego del Fauquí y Mayor y cortó el tráfico por la rafa-puente. Al encontrarse la villa sin fondos económicos, las reparaciones propuestas fueron provisionales. ${ }^{13}$ Las reconstrucciones definitivas se dilataron en el tiempo, coincidiendo con un desfalco de los fondos públicos, la lentitud administrativa y con nuevos problemas que aumentaron la valoración de la obra aprobada de la rafa y de la conducción de aguas. A finales de noviembre de 1791, las intervenciones todavía no se habían concluido. La dilación de las obras afectó a la agricultura ante la falta de aguas para el riego y la sequía, así que en 1788 se condonó un tercio del equivalente por las malas cosechas y al arrendatario de la exportación de los frutos se le compensó por las pérdidas.

Mientras los ciudadanos digerían los desastres de la avenida de 1785, en 1786 una población mermada en defensas volvió a ser víctima de las fiebres tercianas estivales, como sus vecinas Monforte del Cid y Alicante. El balance para Aspe fue de 180 enfermos y 1 fallecido. ${ }^{14}$

El último decenio del siglo se inició con la sequía de 1792, pero las esperadas precipitaciones se tradujeron a inicios de septiembre de 1793 en una lluvia torrencial, que derivó en la avenida más importante sufrida por la villa durante el setecientos y, para postre, culmen de todos los desastres que los vecinos acumulaban sobre sus espaldas.

\section{LA AVENIDA DEL 8 DE SEPTIEMBRE DE 1793}

\subsection{Del episodio a la Real Provisión de 31 de mayo de 1794}

Durante los días 7 y 8 de septiembre de 1793 un fuerte aguacero se hizo presente en diferentes poblaciones valencianas originando graves pérdidas materiales y económicas. La ciudad de Alicante no sufrió desperfectos; sin embargo, las intensas lluvias se hicieron notar en toda la comarca y azotaron tanto a las vías de comunicación como a las huertas e infraestructuras circundantes. El azud de Mutxamel, las producciones hortícolas y el resto de infraestructuras cercanas quedaron dañadas tras superar el agua en más de dos metros la pared del pantano de Tibi. Alcoy también se vio afectada por la crecida del Serpis, la cual destruyó el puente de piedra y afectó a sus diferentes molinos. ${ }^{15}$ La riada no tuvo piedad con el pantano de Elche y destrozó, entre otras cosas, su portón. Situación parecida se conoció más tarde en Elda, cuando en la primera semana de octubre la presa no pudo soportar la cantidad de aguas retenidas tras las

13. AHDPA: Correspondencia relativa a la hacienda municipal. Informes y recursos (1762-1830), legajo 12610, Informe de Yrujo sobre el expediente de Aspe. Madrid, 19 de diciembre de 1785.

14. Alberola Romá, A.: Catástrofe, economía y acción política en la Valencia del siglo XVIII. Valencia: Institució Alfons el Magnànim, 1999, p. 255.

15. Ibídem, pp. 311-314. 
últimas avenidas fluviales y quebró. ${ }^{16}$ Finalmente, conocemos los graves perjuicios que se localizaron en la Vega Baja del Segura, subrayando el caso de Callosa del Segura.

Aspe recibió la tormenta la madrugada del 8 de septiembre con unos resultados fatídicos. El término municipal se inundó, las corrientes formaron arrastres que dañaron los cultivos arbóreos de la ciudad: olivares, vides, higueras y almendros; aunque el resto de producciones de la villa tampoco corrieron una mejor fortuna. La destrucción incluyó igualmente a las casas de campo, que perdieron todo lo que almacenaban en su interior: utillaje de trabajo, grano, aceite, vino y cabezas de ganado; por lo tanto, los campesinos se encontraban en la ruina. Seriamente afectado quedó todo lo que se ubicaba cerca de la rambla del río Tarafa, que una vez desbordada, llegó a afectar a los cimientos de las casas construidas junto a su ribera y dejó inservibles sus bienes materiales. El torrente formado en la rambla tampoco tuvo piedad de las infraestructuras hidráulicas y viarias. La peor suerte la corrió el puente del Baño, que tantas décadas había costado reconstruirlo. Destino similar obtuvo la rafa-puente del Fauquí, al encontrarse en un estado endeble tras las pasadas avenidas. Por último, el acueducto del Hondo de las Fuentes, ubicado en el barranco, perdió sus conducciones, al igual que las acequias de la villa. ${ }^{17}$

Para intentar aplacar el aguacero la villa de Aspe llevó a cabo una rogativa pro serenitate en búsqueda de una intercesión divina. A la hora de rogativas los aspenses se encomendaban en tiempos de sequía a su patrona Virgen de las Nieves, pero para esta avenida no pudieron recurrir a ella. La razón era que su ermita se encontraba a varios kilómetros del pueblo y se necesitaba la autorización del obispado de Orihuela. El sustituto fue otro de los símbolos relevantes de la religiosidad barroca, la Sagrada Forma. Lo más probable es que se utilizara la custodia procesional donada por el Marqués de Elche el año 1790.

Una vez pasada la tempestad, no llegó la calma. El pueblo se encontraba totalmente aislado al quedar destrozadas las infraestructuras viarias. Tampoco se disponía de agua potable tras la destrucción de la rafa y los canales que la conducían a la fuente de la Plaza Mayor. Asimismo, había carencia de víveres, ya que fueron arrasados por el torrente y tropezaron con la inutilidad de los molinos harineros próximos. A todo ello, la agricultura, principal riqueza de la villa, no solamente había perdido parte de sus cultivos, también el frágil estado que tenían las infraestructuras de riego haría imposible abastecerla de agua en el futuro inmediato.

Buscando una solución urgente la villa celebró diferentes Juntas, que no cristalizaron ante la debilidad económica que se arrastraba como consecuencia de los infortunios sufridos en las últimas cinco décadas. Vista la situación, Francisco Pasqual Belda, vecino de la villa, se ofreció para adelantar el importe de los costes de las obras durante dos años. Para su reintegro proponía la cesión de los fondos de la contribución del

16. Navarro Pastor, A.: Historia de Elda. Alicante: Publicaciones de la Caja de Ahorros Provincial, 1981, vol. I, p. 273.

17. Archivo Histórico Nacional (AHN). Consejos, legajo 22859, Memorial de Francisco Pasqual Belda al Consejo de Castilla. Aspe, 27 de octubre 1793. 
equivalente que hacía la villa durante diez años, el uso del sobrante de propios y el dinero anual que la villa destinaba a la Junta de Caminos de Orihuela. ${ }^{18}$

La propuesta fue enviada por el propio vecino al Consejo de Castilla para buscar su aprobación y la autorización del uso de los fondos, ya que no podemos olvidar que las haciendas municipales y obras públicas quedaban bajo el control del gobierno central desde la creación de la Contaduría General de Propios y Arbitrios en 1760. El ofrecimiento de Belda llama la atención al ser un enriquecido tratante que no era natural de Aspe, sino de Bocairente, y casado con una aspense. Su «generosidad» cabría enmarcarla en la búsqueda de reconocimiento social en la localidad por parte de un foráneo y que, como veremos, tuvo grandes consecuencias.

La situación de penuria en la cual había quedado Aspe queda en evidencia ante la petición de un arrendatario de tierras, que pidió una compensación económica por las tandas de riego que había perdido por la rotura de la acequia Mayor. ${ }^{19}$ Perjuicio similar vivió el arrendatario del mesón del año 1793, el cual reclamó una rebaja económica ante el descenso de tráfico de carruajes y arrieros a raíz de la destrucción del puente del Baño. ${ }^{20}$ Verificados ambos casos obtuvieron respuesta positiva del Consejo de Castilla.

Llegado el expediente de Belda sobre las destrucciones en la villa y su propuesta de financiación de las reparaciones al Consejo de Castilla, se inició una investigación para contrastar la información. Esta institución destinó para tal efecto al capitán general de Valencia, Duque de la Roca, ${ }^{21}$ que encargó a la Junta de Policía la elaboración del informe. La pesquisa corroboró los destrozos de las carreteras e infraestructuras hidráulicas y recalcó la necesidad de su reparación ante la urgencia de recuperar el transporte por el barranco y el cultivo de la huerta. También recomendó que se enviara un especialista para programar las obras, calculadas inicialmente en unos 14.000 pesos. En cuanto al vecino, la Junta de Policía dio visto bueno a su ofrecimiento y propuso que fuera el inspector de las obras. ${ }^{22}$

Analizada la investigación por el alto organismo, la propuesta fue aprobada el $12 \mathrm{de}$ marzo de 1794. Se agradeció a Belda su «patriotismo» y fue informado de que se enviaría un arquitecto para elaborar planos y presupuestos, separando el gasto público del privado. Una vez que el arquitecto hubiera terminado su trabajo, las obras de reconstrucción tendrían que iniciarse inmediatamente. Para el reintegro de los caudales deberían celebrarse Juntas, que establecieran los arbitrios más equitativos y moderados para el pago

18. AHN: Ibidem.

19. AHDPA: Correspondencia relativa a la hacienda municipal. Informes y recursos (1762-1830), legajo 12610, El conde de Zanoni a Juan de Membiela. Valencia, 3 de noviembre de 1794.

20. AHDPA: Correspondencia relativa a la hacienda municipal. Informes y recursos (1762-1830), legajo 12610, El conde de Zanoni a Juan de Membiela. Valencia, 14 de abril de 1794.

21. El trabajo biográfico más completo de los personajes que ocuparon cargos en la administración e instituciones valencianas durante el setecientos es el de GIMÉNEZ LÓPEZ, E.: Los servidores del rey en la Valencia del siglo XVIII. Valencia: Institució Alfons el Magnànim, 2006.

22. AHN: Consejos, legajo 22859, Informe de la Junta de Policía de Valencia sobre las destrucciones en Aspe para el fiscal del Consejo de Castilla. Valencia, 30 enero de 1794. 
de las obras públicas. Posteriormente, se encargó al intendente poner en marcha las tres tareas que fijaba la Real Provisión del 31 de mayo de 1794: elegir un arquitecto, recabar información sobre Belda y mandar que se constituyeran Juntas en la villa de Aspe.

\subsection{El fracasado proyecto de V. Gascó y la celebración de Juntas}

A primeros de julio de 1794, una orden desde la capital recordó al intendente interino, conde de Zanoni, que debía aplicar lo que se le había encargado por la Real Provisión. Poco tiempo después, el agente territorial nombró como arquitecto encargado de las obras y planos a Vicente Gascó, ${ }^{23}$ con gran experiencia en esta materia. Seguidamente, envió a Aspe la orden de formar Juntas, para las cuales el Consejo le recomendaba que participaran uno o dos representantes de la Junta de Aguas, ${ }^{24}$ algunos terratenientes y quien creyera oportuno. En último lugar, ordenó al corregidor elaborar el informe acerca del vecino aspense.

Una vez recibida la orden, Vicente Gascó partió de inmediato hacia la villa y realizó una declaración, fechada en octubre de 1794, sobre las intervenciones necesarias en Aspe. El proyecto fue aprobado por la Junta de Comisión de Arquitectura el 26 de enero de 1795, que calculó el trabajo del arquitecto en 292 libras.

El informe contenido en la declaración evidenció que el viaducto del Baño no pudo soportar la fuerza de las aguas de la avenida debido a dos motivos: disponer solamente de un arco de muy poca elevación y por la ubicación en el estribo de una acequia. Ante la imposibilidad de reconstruir el antiguo puente, V. Gascó planificó uno nuevo con un ojo de 70 palmos de luz y 34 palmos de ancho. El material usado para los pilares sería piedra labrada en su parte exterior a soga y tizón y los restantes mediante el uso de sillarejos y mampostería. En cuanto a su bóveda, se construiría en sillería con forma elíptica. Para prevenir posibles filtraciones no quedaba más remedio que desviar la acequia que cruzaba el puente e incluir un sistema de desagüe con tres canales. La última medida de protección se basaba en eliminar un terraplén y dos casas cercanas, al ser un impedimento para la ubicación del nuevo viaducto. ${ }^{25}$

23. Entre otros cargos fue Director de la Academia de Nobles Artes de San Carlos, Arquitecto del Real Patrimonio y Arquitecto del Real Palacio de Valencia. Su participación en reconstrucciones causadas por avenidas fue constante, así en 1790 había pasado por Aspe para reconocer las obras de reconstrucción de la rafa tras la avenida de 1785. En cuanto a los daños por las lluvias torrenciales de 1793, también realizó los planos de reconstrucción del pantano de Alicante y de la presa de Mutxamel. Para ampliar información sobre el arquitecto ver JANINI DE LA CUESTA, Á.: Las trazas y la obra del arquitecto Vicente Gascó. Col. Tesis doctorals en microfitxes. Valencia: Universitat de València. 1994.

24. La Junta de Aguas de Aspe aprobó su reglamento el 14 de marzo de 1793, concediendo el Ayuntamiento autonomía a los regantes sobre la gestión de las infraestructuras hídricas. Para consultar una trascripción de su reglamento ver MARTínEZ ESPAÑOL, G.: «El regadío en Aspe en época moderna. Constitución de la Junta de Regantes en Sociedad Privada, 1793»), en La Serranica, n. ${ }^{\circ} 47$ (2006), pp. 140-153.

25. AHDPA: Correspondencia relativa a la hacienda municipal. Informes y recursos (1762-1830), legajo 12610, Declaración de Vicente Gascó sobre las obras a realizar en la villa de Aspe. Aspe, 10 de octubre de 1794 
La rafa-puente del Fauquí se encontraba en un estado muy precario y, aunque se pusieron en marcha medidas provisionales, su revisión era constante. El arquitecto no recomendaba actuar sobre los boquetes del muro, pues seguiría siendo algo provisional y posible víctima de otra avenida. Vista la situación, propuso construir un nuevo azud con un paredón de 400 palmos de longitud, 32 de elevación y con un grueso superior de 24. Con la intención de evitar daños por futuras avenidas, la mejor opción era levantar el paredón en sus extremos entre 5 ó 6 palmos. Para que la caída de las aguas no afectara a los cimientos de la construcción, se colocaría a 4 varas de ésta una fila de estacas con puntas metálicas para resistir la fuerza de las aguas. Como la rafa también era usada para transportar agua potable a la villa mediante una cañería, era preciso construir una nueva ubicada debajo de las losas de la parte superior del paredón. Con el fin de continuar su uso a modo de puente, un nuevo terraplén tendría que erigirse en toda la anchura de la carretera hasta la pared del azud. Además, debería levantarse un muro en el lado de las avenidas para contener el terraplén y de paso detener las aguas que se conducirían por las acequias. ${ }^{26}$

El acueducto que transportaba las aguas de la rafa a través del barranco había perdido sus canalizaciones y provisionalmente fueron sustituidas con canales de madera. El resto del trayecto se encontraba con filtraciones, por lo que el agua se contaminaba con las inmundicias cercanas y podía convertirse en foco de enfermedades. La solución planteada consistía en reparar la conducción del acueducto, debido a que la obra provisional no podría resistir una pequeña avenida. Finalmente, el arquitecto creyó conveniente que la nueva cañería que marchaba a la fuente de la Plaza Mayor tendría que tener tres ramales para que otras zonas de población dispusiesen de agua potable. Las nuevas fuentes se ubicarían en la calle San Roque, Barranco y Plaza de los Álamos. ${ }^{27}$

La propuesta de V. Gascó para la distribución de los costes de las obras fue la siguiente:

\begin{tabular}{|l|l|c|}
\hline \multicolumn{1}{|c|}{ Obra } & Organismo financiador & Coste \\
\hline Puente del Baño. & \multirow{2}{*}{$\begin{array}{l}\text { Nuevo terraplén para cruzar el Camino de Caminos de Orihuela. } \\
\text { Real junto al azud. }\end{array}$} & 28.680 libras. \\
\cline { 1 - 1 } Muro del azud del Fauquí. & $\begin{array}{l}\text { Regantes, dueños de aguas y } \\
\text { conde de Altamira. }\end{array}$ & 22.700 libras. \\
\hline Cañería de agua potable. & \multirow{2}{*}{ Fondos propios de la villa. } & 1.400 libras. \\
\hline Acueducto y tres nuevas fuentes. & & 17.000 libras. \\
\hline
\end{tabular}

Fuente: AHDPA: Correspondencia relativa a la hacienda municipal. Informes y recursos (1762-1830), legajo 12610, Declaración de Vicente Gascó sobre las obras a realizar en la villa de Aspe. Aspe, 10 de octubre de 1794. Elaboración propia.

26. AHDPA: Ibídem.

27. AHDPA: Correspondencia relativa a la hacienda municipal. Informes y recursos (1762-1830), legajo 12610, Declaración de Vicente Gascó (...). 
Una vez elaborado el informe y los planes de reconstrucción, la villa de Aspe todavía debía formar Juntas para decidir la financiación de los costes. Sin embargo, se encontraron ante el problema del número de hacendados que debían participar en ellas, ya que la villa disponía de un alto número y, mientras tanto, la Junta de Aguas, por medio de sus vocales, presionaba para poder tener peso en las decisiones. Para poner fin a esta incógnita, se dirigieron al intendente para que les diera una solución. Lo llamativo fue que el conde de Zanoni, pese a tener el poder de decisión dado por el Consejo, les remitió a éste. La villa, ante esta situación, canalizó sus dudas al alto organismo a finales de enero de 1795. Meses después la respuesta del Consejo fue tajante: acusó a su agente territorial de despreocuparse de su trabajo cuando tenía todas las facultades cedidas para el mismo e informó a Aspe de las directrices que le había dado. Tras este incidente, el intendente fijó en 24 personas las que debían representar a los intereses de los propietarios en las Juntas.

Tras los retrasos ocasionados por las contradicciones administrativas, las Juntas se constituyeron el 13 de julio de 1795. Estuvieron integradas por la corporación municipal, los síndicos y 24 representantes de los hacendados. Las Juntas se desarrollaron durante tres sesiones, en las cuales se acordó implementar los planes de V.Gascó y fijar los fondos para el reintegro a Belda.

Las decisiones tomadas fueron las siguientes:

\begin{tabular}{|l|l|l|}
\hline \multicolumn{1}{|c|}{ Sesión } & \multicolumn{1}{|c|}{ Temática } & \multicolumn{1}{c|}{ Acuerdos alcanzados } \\
\hline $\begin{array}{l}12 \text { de julio } \\
\text { de } 1795\end{array}$ & $\begin{array}{l}\text { Reconstrucción del puente } \\
\text { del Baño. }\end{array}$ & $\begin{array}{l}\text { Se reintegrarían los costes a Belda con el } \\
\text { dinero que aportaba la villa anualmente a la } \\
\text { Junta de Caminos de Orihuela. }\end{array}$ \\
\hline $\begin{array}{l}13 \text { de julio } \\
\text { de } 1795\end{array}$ & $\begin{array}{l}\text { Acueducto, canalización } \\
\text { de las aguas potables y las } \\
\text { nuevas fuentes. }\end{array}$ & $\begin{array}{l}\text { Quedó fijado el uso del sobrante de propios } \\
\text { hasta reintegrar el dinero cedido por Belda. } \\
\text { Éste propuso el arbitrio de más caudales, pero } \\
\text { se desestimó. }\end{array}$ \\
\hline $\begin{array}{l}26 \text { de julio } \\
\text { de } 1795\end{array}$ & $\begin{array}{l}\text { Nueva rafa, la cañería que } \\
\text { debía incluir y el camino } \\
\text { que la cruzaba. }\end{array}$ & $\begin{array}{l}\text { Los pagos de reintegro al vecino recaerían } \\
\text { sobre los dueños de aguas de todas las huertas, } \\
\text { aunque hubo opiniones en contra de la } \\
\text { decisión. }\end{array}$ \\
\hline
\end{tabular}

Fuente: AHDPA: Correspondencia relativa a la hacienda municipal. Informes y recursos (1762-1830), legajo 12610, Copia de las Juntas realizadas en la villa de Aspe. Aspe, posterior al 26 de julio de 1795. Elaboración propia.

\subsection{El nuevo puente del Baño y las luchas de poder}

La lentitud en la toma de decisiones retrasaba la reconstrucción del puente del Baño. La única intervención provisional conocida fue la de la Junta de Caminos, la cual creó unas rampas que cruzaban el barranco; aunque la medida había sido demasiado precaria para solucionar el problema del transporte. De todas maneras, la villa sabía que el puente que proyectaría el arquitecto sería demasiado caro y Belda no podría adelantar una cantidad de dinero tan alta en un período tan corto. Por este motivo, el procurador síndico general propuso, durante el cabildo del 6 de julio de 1795, la 
construcción de un puente provisional para que se normalizara el tráfico comercial así como la recogida de frutos en la huerta. Con el objetivo de costear el nuevo proyecto, se dirigirían a la Junta de Caminos con el fin de que ésta cediera el caudal anual de Aspe del año presente y el necesario de los siguientes. En el caso de negativa de ésta, recurrirían al monarca. Con la necesidad de que se iniciaran de manera inmediata las obras se propuso que Belda, convertido en 1795 en alcalde primero ordinario, cediera los caudales necesarios y fuera el comisario de la obra. Tanto el de Bocairente como el resto de la corporación municipal dieron el visto bueno. ${ }^{28}$

La Junta de Caminos de Orihuela se había mantenido reacia a participar desde las primeras propuestas de financiación tras la avenida. Ya en marzo de 1795 el presidente de la Junta de Caminos y corregidor de Orihuela, Juan Lacarte, argumentó que la institución estaba realizando una carretera en Fuente la Higuera bajo la administración de la Dirección General de la Renta de Correos y Caminos, a cuya contaduría rendía cuentas, y que dependía de la Superintendencia General. El corregidor defendía que la obra proyectada por V. Gascó, al ser un puente, quedaba fuera de sus competencias y dependía del Consejo, pues, supuestamente, a la Junta le atañían únicamente las carreteras. Así que recordó a Aspe que debía cumplir con su cuota anual para proseguir la carretera en Fuente la Higuera. ${ }^{29}$ La corporación municipal tenía claro que para la construcción del viaducto provisional esta institución también se opondría, por lo que la villa se dirigió al rey para pedir la cesión del pago que hacía anualmente a la Junta de Caminos. Sobre esta petición no se conoció respuesta, pero Belda usó los fondos destinados a la Junta de Caminos para el nuevo puente.

La obra se inició con rapidez con el acopio necesario de madera, cal y yeso. En el mes de noviembre solamente quedaban por colocar el piso, las barandillas y las rampas. Entre finales de año e inicios del siguiente el puente estaba ya en funcionamiento.

El fin de 1795 supuso que el viaducto ideado por V.Gascó quedara en el olvido, debido a su alto precio, a la negativa de la Junta de Caminos a colaborar y al inicio de pugnas en la villa vinculadas a la dirección de las obras. Todos estos factores fueron argumentos suficientes para dar al traste con cualquier opción de su puesta en marcha. Ahora bien, las disputas no habían acabado, la financiación del puente provisional iba a ser el nuevo foco de tensiones.

El punto de partida del conflicto coincidió con las ansias de poder de Belda. Éste, teniendo presente que su cargo municipal estaba próximo a agotarse, presentó un recurso al Consejo con la finalidad de mantenerse como alcalde y, de esta manera, continuar influyendo en la vida política y económica de la villa. A raíz de este objetivo, rápidamente aparecieron voces discordantes desde la Junta de Aguas para que el vecino dejara de inmiscuirse en cuestiones ajenas, porque preferían que la obra de la rafa fuera por

28. AHDPA: Correspondencia relativa a la hacienda municipal. Informes y recursos (1762-1830), legajo 12610, Cabildo del 6 de julio de 1795. Copia de Antonio Hernández y Miralles. Aspe, 5 de noviembre de 1795 .

29. AHDPA: Correspondencia relativa a la hacienda municipal. Informes y recursos (1762-1830), legajo 12610, El corregidor de Orihuela Juan de Lacarte al intendente Azpiroz. Orihuela, 25 de marzo de 1795. 
subasta pública. Esta institución informó al Consejo de que, a su parecer, el alcalde había manipulado las cuentas del nuevo viaducto con el fin de mantenerse en el poder, puesto que los 12.000 reales de vellón del fondo de la Junta de Caminos no se habían invertido en el puente provisional, sino que se había financiado con dos corridas de toros y la ayuda de los vecinos trayendo piedra y madera de los olmos y álamos. ${ }^{30}$ Analizadas las dos posturas anteriores, el alto organismo decidió no renovar a Belda en el cargo.

La situación se volvió todavía más compleja cuando en 1796 la Junta de Caminos reclamó a la villa de Aspe los 12.000 reales de vellón que adeudaba de 1795 y parte de 1794. Ante la orden de pago, Belda argumentó al Consejo que el uso de estos fondos se debió a la urgencia de construir el viaducto principal de la villa y que, además, se le debían reintegrar los 30.000 reales de vellón que defendía había cedido para su construcción. Pese a esta explicación, el fiscal del Consejo dictaminó en abril que el vecino pagara los 12.000 reales de vellón.

La cuestión sobre estos fondos se agudizó en 1797, a raíz del recurso presentado por Belda en los tribunales. Para la nueva pesquisa se ordenó al intendente que investigara sobre la procedencia de ese dinero y en qué estado se encontraba el puente provisional. Con la misión de clarificar la situación, desde la villa se envió un informe que mostraba muchas contradicciones. Por un lado, la corporación municipal y la Junta de Aguas de 1797 manifestaron que no tenían cuentas que avalaran que el vecino hubiera cedido dinero para el viaducto, aunque tenían constancia de que se invirtió trabajo de los vecinos portando piedra y leña. Por otro lado, el alcalde segundo y regidor en 1795 sumados a algunos vecinos expusieron que el antiguo alcalde había invertido de su patrimonio dinero para el puente provisional. ${ }^{31}$ A tenor de la poca claridad que presentaba la documentación enviada por Aspe, el intendente no tuvo más remedio que pedir a Belda que presentara los costes de la obra. Tras la desconfianza mutua entre ambos bandos, se enviaron las cuentas a finales de año.

El informe de la inversión económica efectuada en el puente pasó a manos del Consejo a mediados de 1798. El nuevo viaducto se calculó en 18.524 reales de vellón y 13 maravedíes a los que se sumaban 2.632 reales de vellón y 33 maravedíes del trabajo de los vecinos y otros ingresos. ${ }^{32}$ En cuanto a su estado, se resaltó su buena construcción, pues había sufrido solamente pequeños daños tras la crecida del río acaecida en 1797. Una vez estudiados los gastos, el intendente recomendó que la Junta de Caminos cargara con el reintegro de los 18.524 reales de vellón a Belda, a pesar de los pocos documentos de los costes que había presentado. Como era de esperar, la Junta de

30. AHN: Consejos, legajo 22859, Recurso de Domingo Gómez Serrano al Consejo. Madrid, 16 de diciembre de 1795.

31. AHDPA: Correspondencia relativa a la hacienda municipal. Informes y recursos (1762-1830), legajo 12610, El intendente Azpiroz a la Justicia, Ayuntamiento y Junta de Propios de Aspe. Valencia, 21 de julio de 1797.

32. AHDPA: Correspondencia relativa a la hacienda municipal. Informes y recursos (1762-1830), legajo 12610, El intendente Azpiroz a Manuel Antonio de Santiesteban. Valencia, 6 de septiembre de 1798. 
Caminos se opuso, pero la propuesta del intendente de reintegro a Belda fue aceptada por el Consejo.

Concluido este largo litigio, Belda había conseguido limpiar su imagen social en el municipio. Su triunfo quedó constatado con el desarrollo de diferentes cargos, como fue el de comisionado de policía y caminos de la villa de Aspe. ${ }^{33}$

Por último, la vida del puente fue larga, porque la construcción de un nuevo viaducto en la zona del Baño se alargó hasta casi la mitad de la centuria, $\mathrm{y}$, para postre, al poco de finalizarse fue arrasado por una avenida el 4 de diciembre $1854 .{ }^{34}$

\subsection{La reparación de la rafa-puente del Fauquí y otras infraestructuras hidráulicas}

Mientras la villa esperaba la finalización de los planes de reconstrucción de las infraestructuras hidráulicas por parte de V. Gascó, se procedió sobre ellas de manera provisional. Las canalizaciones que llevaban aguas potables a la fuente de la villa, ubicada en la Plaza Mayor, fueron reparadas con madera. Asimismo, se actuó sobre la rafa usando estacas de madera y barro, pero pese a los esfuerzos las fugas de agua eran constantes.

Una vez presentado el proyecto del arquitecto sobre la nueva rafa, fue aprobado en las Juntas. Se acordó que tendrían que participar en su coste los dueños de los bancales del Fauquí, los medianos de la propia huerta y las tierras de viñas y olivares del propio partido. En cuanto a los de la Huerta Mayor y Aljau, deberían participar los dueños de bancales, las tierras medianas y las tierras de viñas y olivares. La distribución del pago fue fijada en una cuarta parte para los del Fauquí y los de la Huerta Mayor, mientras que los del Aljau financiarían el resto. A pesar de esta decisión inicial, a primeros de diciembre de 1795 volvieron a emerger las discrepancias. Los que usaban las acequias de la Huerta Mayor y Aljau no dependían exclusivamente de la del Fauquí, la cual tomaba las aguas de la rafa. Además, los de tierras medias y los que cultivaban viña compraban agua de otras acequias. A todos estos debates internos, se unió la negativa de la Junta de Caminos de Orihuela a pagar las 4.400 libras de la nueva rafa, dado que también se usaba como puente. De todas maneras, aunque todavía no estaba clara la distribución del pago, la Junta de Aguas se dirigió al Consejo para que se nombrara un director de las obras del azud y que se realizara por remate en vez de por administración. Justificaban realizar la obra por subasta pública al ser ésta más barata y segura, puesto que Belda no les parecía una persona de fiar y, para colmo, el caudal que había cedido era insuficiente para una obra de urgencia. ${ }^{35}$

El cúmulo de inconvenientes hizo que el proyecto del nuevo azud planificado por V. Gascó quedara en punto muerto. Tras abortarse el plan anterior, las sucesivas reparaciones provisionales por medio de estacas y barro continuaron, mas su función

33. MARTínez ESPAÑOL, G.: Las comunicaciones, el transporte..., p. 82.

34. Cremades CRemades, M. op. cit., p. 117.

35. AHN: Consejos, legajo 22859, Recurso de Domingo Gómez Serrano al Consejo. Madrid, 16 de diciembre de 1795. 
de puente continuaría en una situación endeble y la conducción de aguas se mantendría con canales de madera. En este estado de fragilidad, la crecida del Tarafa el día 14 de noviembre de 1797 volvió a hacer mella en la rafa.

Los primeros años de la nueva centuria fueron críticos tanto a nivel político como económico, no sólo la sequía asolaba los cultivos, sino que la fiebre amarilla que sufría Alicante y Cartagena, desde agosto de 1804, impedía la comercialización de éstos. Ante tal situación, el arrendatario de la exportación de los frutos pidió una rebaja del precio del arriendo. ${ }^{36}$

Bajo esta coyuntura, en 1805 el Ayuntamiento de Aspe y la Junta de Aguas intentaron reparar de forma consistente la rafa del Fauquí. Con esa meta se dirigieron al Consejo para la cesión del uso del sobrante de propios e invertirlo en un proyecto realizado por el arquitecto Juan Francisco Alcaraz de Llopis y el maestro alarife Antonio Cañizares. A pesar de la presentación del plan, el Consejo prefirió enviar al arquitecto Juan Bautista La Corte para el análisis de la situación de la rafa y el resto de conducciones que dependían de sus aguas.

El informe elaborado por J.B. La Corte resaltaba que la rafa se encontraba en una situación ruinosa. La zona dañada por la avenida de 1793 era la misma que en 1751, reparada en los años setenta y principios de los noventa. El paredón se encontraba destruido desde 1793, porque su endeble cimentación no pudo soportar la fuerza de las aguas. El consumo de agua potable de la villa se mantenía a través de precarias conducciones de madera, cuyas constantes reparaciones habían ocasionado un gasto de 4.833 reales de vellón. El camino que cruzaba en dirección a Madrid por la presa y terraplenes cercanos estaba inhabilitado, por lo que se procedió por parte de la Junta de Caminos a reconstruir en las proximidades el puente existente; sin embargo, no había soportado las siguientes avenidas y estaba destruido. Por último, con el objetivo de garantizar las aguas para la acequia del Fauquí, las estacas y la tierra seguían como la única opción implementada. ${ }^{37}$

Como podemos observar, poco o nada había cambiado en el otoño de 1805 tras la avenida de 1793. Las obras provisionales en la rafa ya habían costado más de 50.000 reales de vellón y el tráfico estaba cortado al desaparecer el puente provisional.

En cuanto a las nuevas obras, tenían como objetivo no solamente reconstruirlo, sino también prepararlo para poder resistir futuras avenidas. La fuerza de éstas habían dañado los cimientos, así que la intervención más importante consistía en construir una escalinata capaz de prever este daño y lograr que el salto que provocaban las avenidas no fuera tan alto. Seguidamente, se debería fortificar una parte del muro dañada con un contrafuerte, una vez desaguado y cubierto un gran charco cercano. Para el abastecimiento de agua potable de la villa, se introduciría una nueva cañería bajo el pavimento

36. AHDPA: Correspondencia relativa a la hacienda municipal. Informes y recursos (1762-1830), legajo 12610, El intendente Urbina y Urbina a la Justicia y Junta de Propios de Aspe. Valencia, 13 de marzo de 1805 .

37. AHDPA: Correspondencia relativa a la hacienda municipal. Informes y recursos (1762-1830), legajo 12610, Proyecto de reparación del azud del Fauqui de Juan Bautista La Corte. 20 de septiembre de 1805. 
de la presa. Igualmente, era fundamental reconstruir el terraplén de forma firme para retomar el tránsito sobre el barranco. ${ }^{38}$

El último punto del proyecto incluía la petición de la Junta de Aguas de abrir una nueva acequia hacia el Aljau, que tomaría agua de la rafa a través de la del Fauquí. De esta manera, se compensaría la escasez hídrica como consecuencia de su explotación continuada y el desuso del acueducto del Hondo de las Fuentes, todavía destruido.

Los costes de la obra fueron tasados por J.B. La Corte en 18.878 pesos, sin incluir la nueva acequia del Aljau, al ser obra particular. La distribución propuesta del arquitecto para liquidar los pagos quedó de la siguiente manera:

\begin{tabular}{|l|l|l|}
\hline \multicolumn{1}{|c|}{ Obra } & \multicolumn{1}{|c|}{ Financiador } & Coste \\
\hline Canalizaciones de agua potable. & Fondos de propios y arbitrios de la villa. & 7.750 libras. \\
\hline \multirow{3}{*}{ Reparación del azud del Fauquí. } & Propietarios de agua y tierras de huerta. & 3.280 libras. \\
\cline { 2 - 3 } & Dueños de tierras medianas. & 1.920 libras. \\
\cline { 2 - 3 } & Conde de Altamira. & 2.880 libras. \\
\hline $\begin{array}{l}\text { Nuevo terraplén para cruzar el } \\
\text { Camino Real junto al azud. }\end{array}$ & Junta de Caminos de Orihuela. & 1.750 libras. \\
\cline { 2 - 3 } & Común de los vecinos. & 1.298 libras. \\
\hline
\end{tabular}

Fuente: AHDPA: Correspondencia relativa a la hacienda municipal. Informes y recursos (1762-1830), legajo 12610, Proyecto de reparación del azud del Fauqui de Juan Bautista La Corte. 20 de septiembre de 1805. Elaboración propia.

A principios de 1806, se obtuvo permiso para utilizar los sobrantes de propios para el pago de las 18.878 libras del plan. El intendente Urbina ordenó que se depositaran las 7.750 libras que debía contribuir el fondo de propios y comunicó a los vecinos que tendrían que colaborar por tandas en jornales o acarreo de material por valor de 1.298 libras. ${ }^{39} \mathrm{El}$ agente territorial se dirigió también a la Junta de Caminos para informarle de la partida de 1.750 libras que cederían para el nuevo puente cercano a la rafa. La respuesta de este organismo fue que la cuestión era competencia de la Dirección General de Caminos y Correos. Ésta, una vez analizado el asunto, argumentó que la dirección de la carretera que se mencionaba quedaba fuera de la contribución que se hacía a la Junta de Caminos. Por consiguiente, no pagarían esa cantidad fijada. ${ }^{40}$ Menos escollos puso el Conde de la Alcudia quien, una vez enterado de la cantidad que debía aportar, dio orden a su administrador en Aspe de efectuar el pago de las 2.880 libras, ${ }^{41}$ no obstante, el pago nunca se llevó a cabo. La falta de fondos y la nueva negativa de la

38. AHPDA: Ibídem.

39. AHDPA: Correspondencia relativa a la hacienda municipal. Informes y recursos (1762-1830), legajo 12610, El intendente Urbina y Urbina a la Justicia y Junta de Propios de Aspe. Valencia, 9 de marzo de 1806.

40. AHDPA: Correspondencia relativa a la hacienda municipal. Informes y recursos (1762-1830), legajo 12610, El corregidor de Orihuela Lacarte Thibault al intendente Urbina y Urbina. Orihuela, 21 de junio de 1806.

41. AHDPA: Correspondencia relativa a la hacienda municipal. Informes y recursos (1762-1830), legajo 12610, El Conde de la Alcudia al intendente Urbina y Urbina. 2 de abril de 1806. 
Junta de Caminos dejaron en el dique seco el proyecto, así que se empezaron a buscar otras alternativas que no supusieran un coste tan elevado.

Además de todo lo tratado, nuevos problemas brotaron en la villa como consecuencia de la construcción de la nueva acequia del Aljau por parte de la Junta de Aguas. La oposición fue encabezada por el presbítero Cremades, quien remitió al Consejo, en marzo de 1807, una queja a causa de unas supuestas obras ilegales emprendidas por la villa. El denunciante expuso que la Junta de Aguas había recuperado un proyecto de interconexión de las acequias del Fauquí y Aljau abandonado en 1806 por falta de fondos. Por otro lado, manifestaba que se había financiado con la venta de ilegal de agua, al superarse el fondo de 200 libras que marcaba el reglamento de la institución. Ante esta tesitura, el sacerdote reclamaba al intendente que se frenaran las actividades de acopio de materiales y delineamiento. Como solución al problema de la falta de riego en el Aljau, recomendaba reconstruir el acueducto del Hondo de las Fuentes en vez de perjudicar a los propietarios de las tierras con la nueva obra, entre los cuales se incluía. ${ }^{42}$

Una vez que el Consejo recibió la documentación, se puso en contacto con el intendente para que por medio de una Real Provisión informara de la situación de esas obras y decidiera si debían llevarse a cabo. Las presiones de los opositores tuvieron fruto, porque la obra fue suspendida por el intendente hasta que no se aclarara la situación. Seguidamente, el Consejo suspendió la venta de agua el 31 de julio de 1807, al usarse en una obra que estaba parada y que incumplía las ordenanzas de la institución.

La Junta de Aguas no tardó en intentar explicar su punto de vista en dicho conflicto a través del informe que le pidió el intendente. Especificó que la acequia del Aljau era deficitaria en las aguas que llevaba para irrigar toda su huerta y, para colmo, la situación se había agravado por la constante inutilidad del acueducto sobre arcos que conectaba con la acequia del Fauquí. En búsqueda de una solución, la institución aspense se propuso poner en marcha el plan de J.B. La Corte de unir las acequias del Aljau y Fauquí; no obstante, esta obra inicial se canceló por falta de medios. Con el mismo objetivo de llevar aguas a la huerta del Aljau, se modificó parte del trayecto marcado para continuar con las obras proyectadas. Este plan pretendía que se tomaran las aguas directamente de la rafa y se trasladaran con una conducción que marcharía por las orillas del barranco en vez de por el acueducto del Hondo de las Fuentes. Finalmente, subrayaron que la obra había sido aprobada por el Consejo y peritada en 3.368 libras, incluyendo las 400 libras del valor de la tierra para el tránsito.

En cuanto a las acusaciones de que habían realizado acopio de materiales e iniciado la obra, la Junta de Aguas defendió que simplemente midieron el terreno sin recibir queja alguna de los propietarios. La imputación de las irregularidades en la venta de agua también fue rebatida por esta institución, al exponer que su subasta en domingo era lícita y que ese dinero se destinaba a las intervenciones de urgencia reguladas por

42. AHDPA: Correspondencia relativa a la hacienda municipal. Informes y recursos (1762-1830), legajo 12610, Real Provisión de 5 de junio de 1807 al intendente Urbina y Urbina para su aplicación. Madrid, 8 de junio de 1807. 
J.B. La Corte, lo que le daba, a su entender, legalidad. Una vez finalizadas las obras, se haría de nuevo el acopio de 200 libras, tal y como marcaba el reglamento. Con estos argumentos dejaban claro que los vetos de las obras y a la venta de agua se tenían que levantar para continuar la necesaria obra de conexión entre ambas acequias. ${ }^{43}$

Toda polémica generada con la nueva acequia del Aljau también sacó a relucir que la Junta de Aguas no sólo había intentado llevar a buen puerto la interconexión de acequias, sino que también había invertido una considerable cantidad de dinero procedente de la venta de agua para reconstruir la ruinosa situación de la rafa del Fauquí. ${ }^{44}$ Con este inesperado ingrediente, la situación se enredó un poco más.

Con toda la información recopilada, el intendente decidió que se volviera a vender agua el 18 de agosto de 1807 y que se continuara con la obra; aunque debido a la anómala situación, se enviaría de nuevo a J. B. La Corte con el objetivo de que se verificaran los trabajos que estaba realizando la Junta de Aguas. El propio arquitecto quedó extrañado ante dicha notificación, porque su proyecto había sido abortado debido a su alto coste.

Poco tiempo después, J. B. La Corte había viajado a Aspe con la finalidad de redactar un informe sobre la marcha de las obras que se estaban realizando y así poder tomar decisiones sobre las mismas. Tras revisar la rafa, éste quedó impresionado al encontrarla reparada en mampostería, incluida la cañería, faltándole sólo la coronación. Quedaban por finalizar los contrafuertes, las escalinatas de fortificación y la acequia que en su plan había proyectado para el Fauquí. Incluso los terraplenes se habían reconstruido. El arquitecto dictaminó que las obras cumplían lo que su plan propuso, aunque faltaban las precauciones contra las avenidas que él había fijado. ${ }^{45}$

En su informe, la Junta de Aguas defendió que la falta de fondos de la villa y la negativa de la Junta de Caminos a pagar cancelaron el proyecto de la nueva rafa proyectada por J.B. La Corte. Como consecuencia de ello y de la necesidad de dar riego y transporte, se decidió ejecutar unas obras provisionales mucho más baratas con el plan anterior como modelo. ${ }^{46}$

La inversión económica de ambos proyectos que presentó la Junta de Aguas de Aspe al arquitecto fue la siguiente:

43. AHDPA: Correspondencia relativa a la hacienda municipal. Informes y recursos (1762-1830), legajo 12610, Informe de la Junta de Aguas al intendente Urbina y Urbina. Aspe, 4 de agosto de 1807.

44. AHDPA: Correspondencia relativa a la hacienda municipal. Informes y recursos (1762-1830), legajo 12610, Ignacio Gutiérrez al intendente Urbina y Urbina. Aspe, 10 de agosto de 1807.

45. AHDPA: Correspondencia relativa a la hacienda municipal. Informes y recursos (1762-1830), legajo 12610, Informe de Juan Bautista La Corte al intendente Azpiroz. 12 de octubre de 1807.

46. AHDPA: Ibídem. 
Tras la tempestad, no llegó la calma: el Medio Vinalopó ante los temporales de septiembre de 1793

\begin{tabular}{|l|l|c|}
\hline \multicolumn{1}{|c|}{ Obra } & \multicolumn{1}{c|}{ Financiador } & Coste \\
\hline \multirow{3}{*}{ Reparación del muro del azud. } & Junta de Aguas. & 15.000 R. vellón. \\
\cline { 2 - 3 } & Vecinos. & Cesión de cal. \\
\cline { 2 - 3 } & Vecinos pudientes. & 2.752 R. Vellón. \\
\hline Terraplén del Camino Real. & Trabajo de 100 vecinos. & No especificado. \\
\hline
\end{tabular}

Fuente: AHDPA: Correspondencia relativa a la hacienda municipal. Informes y recursos (1762-1830), legajo 12610, Informe de Juan Bautista La Corte al intendente Azpiroz. 12 de octubre de 1807. Elaboración propia.

J.B. La Corte entendía que la obra se había realizado sin la aportación económica de muchos que posteriormente se beneficiarían de ella. Bajo esa condición, calculó los gastos que supondrían proteger el azud de avenidas y finalizar su coronación:

\begin{tabular}{|l|l|c|}
\hline \multicolumn{1}{|c|}{ Obra } & \multicolumn{1}{|c|}{ Financiador } & Coste \\
\hline $\begin{array}{l}\text { Conservación de la cañería de la } \\
\text { fuente. }\end{array}$ & Fondos de propios de la villa. & 1297 pesos. \\
\hline \multirow{2}{*}{$\begin{array}{l}\text { Nuevas intervenciones en el azud } \\
\text { del Fauquí. }\end{array}$} & $\begin{array}{l}\text { Propietarios de las aguas y } \\
\text { huertas. }\end{array}$ & 1.066 pesos. \\
\cline { 2 - 3 } & Conde de Altamira. & 1.137 pesos. \\
\cline { 2 - 3 } & Vecinos de Aspe & 900 pesos. \\
\hline
\end{tabular}

Fuente: AHDPA: Correspondencia relativa a la hacienda municipal. Informes y recursos (1762-1830), legajo 12610, Informe de Juan Bautista La Corte (...). Elaboración propia.

El último tema tratado fue la espinosa cuestión de la nueva acequia del Aljau. J.B. La Corte aconsejó realizar esta obra, porque con solamente dos tahúllas de extensión que necesitaba la nueva acequia y con la rafa reparada no se perjudicaría a ningún propietario. Además, ya en su anterior proyecto el propio arquitecto subrayó que esta intervención era muy necesaria para recuperar la huerta del Aljau y evitar que no se enriquecieran de la venta de agua algunos individuos. Quedaba claro que con esta obra proyectada no era aconsejable reparar el acueducto del Hondo de las Fuentes tanto por su alto coste, más de 4.000 pesos, como por el peligro de volver a quedar arruinado con una avenida como la de 1793. Por lo tanto, el análisis de J.B. La Corte desmontaba los argumentos del presbítero Cremades sumado a que ni las obras se habían iniciado y tampoco había tenido lugar un acopio de materiales. ${ }^{47}$

La última información que nos brinda la documentación sobre el proyecto de unión de las acequias del Fauquí y el Aljau data ya de noviembre de 1808. Aspe se dirigió al Consejo para poder construir la interconexión de acequias. Con el fin de consolidar su petición, adjuntaron el informe de J.B. La Corte sobre la necesidad de su construcción en lugar de la del acueducto destruido. Tasaban la obra en unas 200 libras, algo barato y de fácil ejecución. Incluso remitieron las reglas para su coste y uso:

47. AHDPA: Correspondencia relativa a la hacienda municipal. Informes y recursos (1762-1830), legajo 12610, Informe de Juan Bautista La Corte (...). 


\begin{tabular}{|l|l|}
\hline Regla 1 & $\begin{array}{l}\text { Para evitar disputas con los dueños del agua correría la misma cantidad por } \\
\text { ambas acequias. }\end{array}$ \\
\hline Regla 2 & Los dueños de las aguas del Fauquí tendrían derecho a usarla. \\
\hline Regla 3 & $\begin{array}{l}\text { Para su pago contribuirían } 2 / 3 \text { los dueños medianos del Aljau y lo restante los } \\
\text { dueños de tierras sin agua. }\end{array}$ \\
\hline
\end{tabular}

Fuente: AHDPA: Correspondencia relativa a la hacienda municipal. Informes y recursos (1762-1830), legajo 12610, Certificación de la villa de Aspe al Consejo. Aspe, 7 de noviembre de 1808. Elaboración propia.

Llegados a este punto, la documentación no proporciona más información sobre este proyecto de interconexión de las acequias, ignorando si se llevó a cabo. Lo único seguro es que el acueducto del Hondo de las Fuentes sí que fue reconstruido, manteniéndose actualmente uno que data de mitad del siglo XIX, por lo que quizás la obra de las acequias quedó congelada. En lo referente a la rafa, nos encontramos ante la misma situación, no tenemos datos que avalen que el segundo proyecto realizado por Juan Bautista La Corte para la protección contra avenidas se pusiera en marcha. Lo único que podemos constatar es que la rafa fue destruida por una avenida en 1854.

\section{Ilustración 1: El río Vinalopó y sus afluentes}

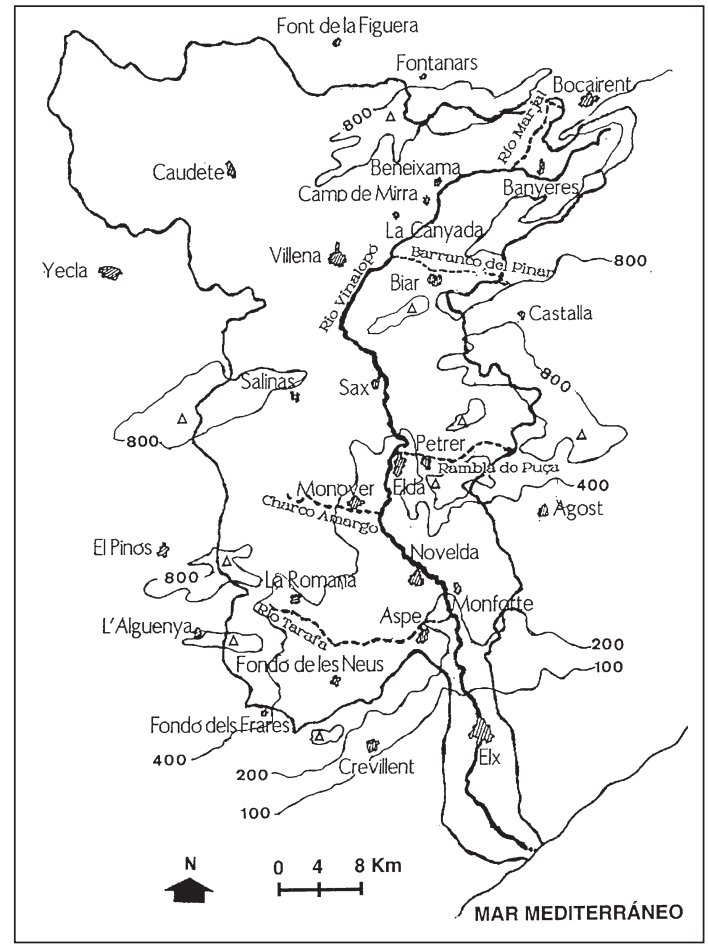

Fuente: PÉRez MedinA, T.: Los molinos de agua en las comarcas del Vinalopó: (1500-1840). Petrer: Centre d'Estudis Locals de Petrer, 1999, p. 20. 